\title{
O Estresse na Pesquisa Epidemiológica: O Desgaste dos Modelos de Explicação Coletiva do Processo Saúde-Doença
}

LUIS DAVID CASTIEL*

\section{Apresentação}

A noção de estresse desfruta de considerável difusão em variados contextos: no chamado "senso comum" - aparece, com freqüência, nos meios de comunicação de massa; no jargão de diversas práticas terapêuticas médicas, psicológicas, fisioterápicas (tanto “convencionais" como "alternativas"); no campo da pesquisas fisiológicas (biomédicas ou não) e epidemiológicas. Nesse nível, a teoria do estresse se constitui num dos referenciais explicativos para abordar o processo saúde-doença. ${ }^{1}$ Diante dessa proliferação de contextos de significação, é inevitável a falta de correspondência entre os sentidos atribuídos ao mesmo conceito. Mas, seria possível chegar a uma definição precisa de estresse, passivel de ampla aceitação no interior das ciências biológicas e na pesquisa epidemiológica? Mais do que isso, a teoria do estresse, inicialmente formulada por Selye, em sua teorização acerca da síndrome geral de adaptação, ${ }^{2}$ e posteriormente desenvolvida por seus seguidores, disporia de valor heurístico para propiciar avanços do conhecimento sobre o adoecer humano?

\footnotetext{
* Professor Assistente do Departamento de Epidemiologia e Métodos Quantitativos em Saúde da Escola Nacional de Saúde Pública. Fundação Oswaldo Cruz. Rio de Janeiro.

1. ALMEIDA Fo. N., Epidemiologia sem números. Rio de Janeiro, Ed. Campus, 1989.

2. SELYE H., "A Syndrome produced by diverse nervous agents". Nature ${ }^{\circ}$ 148, 1936.
} 
Ou assumiria o lugar de um obstáculo epistemológico, na medida em que dificultaria o desenvolvimento de teorizações mais satisfatórias sobre tal processo?

Esta ordem de problemas constitui um dos focos de nosso trabalho. Para encaminhar a discussão, faz-se, primeiramente, uma breve "genealogia" do vocábulo e da teoria do estresse. Além disso, são apontadas algumas questões a respeito do arcabouço teórico-conceitual que envolve a noção e suas limitaçôes, especialmente no que se refere à pesquisa epidemiológica.

Diante da atual realidade da saúde, o estabelecimento do estresse como objeto de estudo da epidemiologia coloca em questão o alcance da disciplina e sua capacidade de deslindar os fatores causais que geram doenças nas populações. São cada vez mais prevalentes quadros de morbi-mortalidade em cuja patogenia assumem destacado papel os estados relacionados ao estresse - imunodepressão, por um lado, e afecções que provocam comprometimentos cárdio e cérebro-vasculares, por outro. Como a leitura do processo saúde-doença mediante a óptica coletiva própria da epidemiologia elide a dimensão singular desses fenômenos, a construção das referidas configurações causais, inevitavelmente, sofrerá limitações em seu teor explicativo. Uma possibilidade de lidar com estas dificuldades teóricas e metodológicas seria utilizar conteúdos de outros campos de saber, numa proposta transdisciplinar. Por exemplo: conceitos da psicanálise e da antropologia podem ser de grande utilidade para se entender a especificidade do potencial simbolizador da subjetividade humana, ao deparar-se com a contingência de enfrentar estímulos (estressores ou não) endógenos (pulsionais) ou exógenos (físicos e/ou sociais). Mas, mais do que isto, é preciso reavaliar as concepções de empreendimento científico que estão subjacentes às propostas investigativas da epidemiologia. Há indícios de exaustão dos modelos teórico-metodológicos baseados no reducionismo das dicotomias originárias da Era Moderna, que não se mostram equipados para perceber o universo composto por relações interatuantes e pela emergência de novos padrões ao se transitar por níveis de organização diferenciados.

\section{A teoria do estresse}

Ao observar a significação original no idioma inglês, percebe-se que o substantivo stress (proveniente da física e da mecânica) já encerra ambigüidades (que permanecem na conceituação biológica). Segundo o verbete dicionarizado pelo Webster's, temos os sentidos de “1. a) força exercida 
sobre um corpo que tende a deformar-se; b) a intensidade desta força" ${ }^{3}$ É curioso notar o fato da força poder conduzir à perda de integridade do objeto ("tende a deformar-se"). Além disso, inclui-se a conotação biológica: “2. a) tensão mental ou física; b) urgência ou pressão que a causa”. ${ }^{4}$ Desta maneira, já há uma dubiedade que cria uma possibilidade inicial de confusão: o mesmo termo se refere tanto à causa como ao efeito. Na língua portuguesa, registra-se o anglicismo "estresse" (que é a forma escolhida para este trabalho) como indicativo da resposta biológica a estímulos perturbadores de uma situação "estável”, ou seja: "Conjunto de reações do organismo a agressões de ordem física, psíquica, infecciosa e outras, capazes de perturbar-lhe a homeostase". ${ }^{5} \mathrm{~A}$ base deste significado está na elaboração desenvolvida inicialmente por Walter Cannon (que, por sinal, apropriadamente intitulou um de seus trabalhos de: Stresses and Strains of Homeostasis). Em linhas gerais: há uma relação de proximidade entre a função neurovegetativa simpática e a atividade emocional. Conforme sua teoria da emergência da emoção, o sistema simpático auxilia o organismo a enfrentar as possíveis agressões à sua integridade. Deste modo, ocorrem modificações fisiológicas subjacentes aos estados de medo, fome, dor, raiva - caracterizados pela "secreção adrenalínica de emergência" ${ }^{6}$ No entanto, percebeu-se que esta abordagem tinha limitações ao se verificar que a indução adrenalínica pode se manifestar como raiva, euforia, medo, ou, até, não ser acompanhada por nenhuma emoção, em pessoas preparadas para isto. ${ }^{7}$

Foi Selye quem construiu o arcabouço da teoria do estresse em sua postulação da "síndrome geral de adaptação", concebida a partir de experimentos com animais. Sucintamente: compõe-se de três fases: 1a) alarme, com dois estágios; a) choque, que corresponde às reações descritas por Cannon (resposta adrenérgica); b) contra-choque, com aumento da atividade do córtex da supra-renal; 2a) resistência, fase de compensação na qual pode haver regressão dos fenômenos descritos; mas permanece a hiperatividade córtico-supra-renal, resultante de estimulação hipofisária; 3a) esgotamento, resultado da falha destes mecanismos adaptativos a

3. WEBSTER'S, New World Dictionary of the American Language. Verbete stress. New York, Collins, 1974.

4. WEBSTER'S., op. cit.

5. FERREIRA A. B. H., Novo Dicionário da Língua Portuguesa. Verbete "estresse". Rio de Janeiro, Ed. Nova Fronteira, 1975.

6. CANNON W. B., Bodily Changes in Pain, Hunger, Fearand Rage. Second ed. New York. D. Appleton \& Co., 1920.

7. MELLO Fo. J., Concepção psicossomática: visão atual. Rio de Janeiro, Ed. Tempo Brasileiro, 1986. 
estímulos recorrentes e excessivos. As alteraçōes características da fase de alarme retornam, mas com diminuição da amplitude e antecipação das respostas, com possibilidade de levar até à morte. ${ }^{8}$ Seguidores de Selye ampliaram a idéia do estresse físico original para o domínio psicológico, ao estudar os efeitos da expectativa de situações onde haveria exigências de desempenho ou ameaça à integridade física (reais ou imaginárias). Há uma profusão de estudos que trazem evidências clínicas e experimentais quanto à influência das informações provenientes do meio social e interpessoal, mediadas pelo sistema nervoso central, que podem provocar modificações no nível bioquímico. Verificou-se, por exemplo, a excreção urinária de derivados dos hormônios da supra-renal em pessoas nas vésperas de provas, competições, intervenções cirúrgicas. ${ }^{9.10}$ Porém, este tipo de dado, por si só, não é suficiente para explicar a ocorrência da doença, resultante de configuraçōes complexas de variáveis intrincadas e interatuantes (que a pesquisa epidemiológica procura separar, dimensionando suas respectivas ponderações etiológicas).

Beck, um autor vinculado à psicologia cognitivista, classifica o estresse psicológico em três categorias básicas. A primeira pode ser subdividida em dois níveis: a) o relacionado com eventos traumáticos avassaladores, que trazem ameaças constantes à vida da pessoa, como nas circunstâncias de combate ou catástrofes; b) o ligado a situações imprevisíveis de ameaça (aparentemente menos avassaladoras), como em dificuldades profissionais ou acadêmicas que ponham em risco status econômico ou social, eventos que perturbem a saúde e o bem-estar ou coloquem em perigo relações interpessoais importantes. A segunda categoria diz respeito a pressões insidiosas, de caráter mais duradouro: o desgaste seria gradual, resultante dos efeitos cumulativos de estímulos persistentes. A terceira é altamente específica para determinados indivíduos: um estímulo particular, que habitualmente não atingiria a maior parte das pessoas, os afeta em demasia, em virtude da forma suscetível com que reagem às contingências da vida. Tais pessoas apresentariam traços ansiosos de personalidade. Além disso, Beck aponta que, em distúrbios psicossomáticos, o estressor seria gerado "internamente" - fenômenos psicológicos de tal ordem que fazem os indivíduos colocarem demandas exageradas sobre si próprios. ${ }^{11}$

8. SELYE H., op. cit.

9. HINIKLE JR. L. E., "Stress and Disease: the concept after 50 years". Soc. Sci.Med. vol. 25 nº6. 1987.

10. MOREIRA M. D. \& MELLO Fo. J., "Psicoimunologia Hoje" in: Psicossomática Hoje. Porto Alegre, Ed. Artes Médicas, 1992.

11. BECK A., Cognitive Therapy and Emotional Disorders. Int. Univ. Press, New York, 1976. 
Esta categoria de pessoas seria a responsável pelo "viés de suscetibilidade", na pesquisa epidemiológica do estresse, como veremos mais adiante.

Mais recentemente, passou-se a empregar a noção de "estresse social", relacionada a vicissitudes próprias das grandes metrópoles modernas: exposição a ruído, aglomerações, isolamento, trabalho entediante e/ou insatisfatório, medo de agressões e assaltos, que se constituiriam em fatores responsáveis pelo adoecimento, especialmente na esfera cardiovascular. ${ }^{12}$ De fato, as sociedades contemporâneas criam diversas situações em que seus integrantes experimentam frustração, conflito, incerteza e insegurança. Estes sentimentos estão relacionados, com certeza, à ocorrência de doenças cardiovasculares nas populações modernas. Além disso, deve-se considerar o sinergismo destes fatores quando associados a dietas que apresentam altos teores de gorduras saturadas e a baixa atividade física. Mas não há possibilidade de se obterem dados empíricos que permitam produzir uma resposta quantitativa à hipótese que relaciona o estresse com as doenças nas sociedades modernas. De qualquer forma, seria possível perceber nas doenças prevalentes que tipo de estresse aparece primariamente envolvido nas suas patogenias. ${ }^{13} \mathrm{Hinkle} \mathrm{Jr.} \mathrm{consi-}$ dera correta a concepção neuro-humoral da teoria do estresse, mas discorda do modelo mecânico relativo às razões que levam o estresse a provocar a doença. A relação de um organismo e seu ambiente consiste, em grande parte, numa "interação comunicativa”. Nas suas palavras: “(...) Não pode haver dúvida de que a forma e a estrutura das sociedades humanas, suas instituições e suas práticas afetam a natureza das doenças humanas que ocorrem entre seus membros. Os mecanismos através dos quais isto ocorre são complexos, múltiplos e interatuantes. O 'estresse psicológico' é apenas uma pequena parte deles (...)." ${ }^{14}$ É dentro desta visão que se localiza o ponto de vista de Cassel, um importante autor na literatura sobre o tema. Ele afirma que "processos de origem social, atuando como estressores não específicos, poderão aumentar a suscetibilidade de determinados (grifo nosso) organismos frente a um estímulo nocivo direto (agente) através de alterações no seu equilíbrio endócrino (...). Os quadros clínicos decorrentes de tal processo não seriam manifestação de um tipo particular de estressor social, mas, sim, do agente microbiano ou físico-químico ao qual o organismo se encontra exposto." ${ }^{15} \mathrm{O}$ fato de Cassel se referir a determinado organismo enfatiza a importância do modo particular como o indiví-

12. MOREIRA M.D. \& MELLO Fo. J., op. cit.

13. HINKLE JR. L. E., op. cit.

14. HINKLE JR. L. E., op. cit.

15. CASSEL J., Psychosocial Processes and Stress: Theoretical Formulation. Int. J. Hlth. Serv.4(3), 1974. 
duo enfrenta o estressor e modula sua reação. Desta maneira, os estressores atuariam conforme sua capacidade de intervir no campo simbólico. Correspondentemente, haveria os "amortecedores" (buffers), que protegeriam os indivíduos dos estímulos excessivos. ${ }^{16} \mathrm{O}$ repertório de expedientes que o organismo utiliza para lidar com os estressores foi chamado de coping mechanisms. Trata-se do modo como cada pessoa percebe e atua diante dos estímulos desta ordem. ${ }^{17}$ Do mesmo modo, isto inevitavelmente indica uma especificidade nos modos de perceber e responder aos estímulos, que podem ou não ser encarados como estressores.

\section{A pesquisa epidemiológica do estresse}

A abordagem epidemiológica de quaisquer eventos demanda, na sua operação, a definição do próprio evento de modo a permitir sua delimitação quantitativa sob o formato de variáveis. Para isto, é imprescindível sua categorização mediante dispositivos taxonômicos. Uma das classificações atualmente muito difundidas em epidemiologia psiquiátrica é o Manual de diagnóstico e estatística de distúrbios mentais (DSM-III-R), ${ }^{18}$ que destaca o papel do estresse sob dois ângulos: primeiro, em um dos eixos de sua avaliação multi-axial - denominado gravidade dos estressores psicossociais - estabelece uma tipologia com seis graus de intensidade: 1 . nenhum; 2. leve; 3. moderado; 4. grave; 5 . extremo; 6. catastrófico, todos referidos a "acontecimentos agudos" (duração de menos de seis meses) ou "circunstâncias duradouras" (duração de mais de seis meses), com exemplos estratificados para adultos e crianças/adolescentes. Para classificar a gravidade do estressor, o DSM-III-R baseia-se "na determinação clínica de stress", "numa pessoa comum", em circunstâncias similares e com valores socioculturais semelhantes que tivesse a experiência do estressor psicossocial particular. Este julgamento envolve considerações do seguinte: a quantidade de mudança, na vida da pessoa, causada pelo estressor; o grau em que o acontecimento é desejado e sob o controle da pessoa; e o número de estressores (...). Mais adiante, são exemplificados "tipos de estressores psicossociais a serem considerados", agrupados sob as seguintes áreas: conjugal, parental, outro interpessoal, ocupacional, circunstância de vida, financeira, legal, do desenvolvimento, doença física ou lesão,

16. HINKLE JR. L. E., "The concept of stress in Biological and Social Sciences." Sci. Med. Man ํํำ, 1973.

17. MOREIRA M.D. \& MELLO Fo. J., "Psicoimunologia Hoje", op. cit.

18. Manual de diagnóstico e estatística de distúrbios mentais. Săo Paulo, Ed. Manole, 1989. 
outros estressores psicossociais, fatores familiares (para crianças e adolescentes). ${ }^{19}$

Em segundo lugar, estabelece uma categoria taxonômica específica, denominada distúrbio de stress pós-traumático, a qual, a exemplo dos "estressores", procura circunscrever, através de uma série de critérios diagnósticos generalizadores (em função de uma suposta concepção de normalidade enquanto distribuição mais frequiente): “A. A pessoa vivenciou um acontecimento que está fora da faixa habitual de experiências humanas e que seria acentuadamente doloroso a quase (nossos itálicos) qualquer um (...); B. O acontecimento traumático é persistentemente revivido" (em pelo menos "uma" de "quatro" maneiras descritas); "C. Evitamento persistente dos estímulos associados ao trauma ou insensibilidade da reatividade geral (não presente antes do trauma)", indicado por, no mínimo, "três" de uma relação de "sete" critérios; "D. Sintomas persistentes de excitabilidade aumentada (não presente antes do trauma)", assinalado por, pelo menos "dois" de uma lista de "seis" critérios. Além disto, é preciso diferenciar categorias correlatas, com as quais deve-se realizar um diagnóstico diferencial: outros distúrbios de ansiedade e distúrbios de ajustamento. ${ }^{20}$

Apesar dos esforços classificatórios do DSM-III-R, da formulação de modelos conceituais - utilizando a conhecida tríade agente/hospedeiro/ambiente e a elaboração de instrumentos para estudar a epidemiologia do que se convencionou chamar de estresse, ${ }^{21}$ não parece ter havido clarificação suficiente do conceito, mesmo diante da considerável produção de trabalhos sobre o tema. ${ }^{22}$ Isto pode ser verificado na detalhada revisão realizada por Kasl. Este autor, em primeiro lugar, emprega uma definição operacional (produzida por Mcgrath), com uma formulação "econômica" que enfatiza a dimensão particular da percepção do estresse: "Substancial desequilíbrio (percebido) entre demanda e capacidade de responder, sob condições onde o fracasso em atender a demanda tem importantes conseqüências (percebidas)." ${ }^{23}$ Porém, Kasl comenta que tal definição sofre de restrições (como qualquer outra), uma vez que o problema de definir um termo primário é transferido para os termos secundários. ${ }^{24}$ Independentemente disto, o citado pesquisador assinala sua preocu-

19. Manual de diagnóstico e estatística de distúrbios mentais, op. cit.

20. Manual de diagnóstico e estatística de distúrbios mentais, op. cit.

21. SUSSER M., "The Epidemiology of Life Stress" in: SUSSER M., Epidemiology, Health and Society. Selected Papers. Londres, Oxford University Press, 1987.

22. KASL, "Stress and Health". Ann. Rev. Publ. Hlth. n 5, 1984.

23. KASL, op. cit. 
pação em se deter no campo metodológico e, mediante um exaustivo levantamento de trabalhos sobre o tema, aponta quatro usos distintos para a idéia de estresse: “a) como uma condição ambiental; b) como a avaliação de uma situação ambiental; c) como uma resposta à condição ambiental ou à sua avaliação; d) como um termo interativo que indica a relação entre demandas ambientais e a capacidade de responder tais demandas". ${ }^{25}$ Ao referir-se a esta falta de consistência, Kasl admite que as tentativas de se alcançarem conceituações mais precisas, apropriadas para a pesquisa científica são insatisfatórias: "Sentimos que algo importante foi deixado de fora: no lado do estímulo, no próprio processo ou no lado da resposta. Por esta razão, a vacilação, a falta de clareza, a ausência de consenso" 26 (nossos itálicos). O que mais chama a atenção neste comentário não é tanto a disponibilidade em perceber as limitações conceituais embutidas na teoria do estresse, mas o fato de sugerir que tal insuficiência pertence a "algo" que ficou "fora". Na verdade, fora das possibilidades de que o instrumento empiricista dispõe para a apreensão totalizante dos fatores que expliquem satisfatoriamente o processo saúde-doença.

Por outra perspectiva, problemas da mesma ordem são abordados por Feinstein ao englobar elementos que ficam fora do controle do pesquisador sob a categoria "viés de suscetibilidade". Nesta rubrica, estão incluídos atributos pessoais, como longevidade familiar e estados ou características psíquicas. Segundo esse autor, tais fatores podem interferir tanto no prognóstico em relação ao agravo estudado como na "escolha da exposição a fatores de risco", "estilo de vida" ou outros agentes etiológicos suspeitos. ${ }^{27}$ Segundo ele, os estados e características psíquicas são extremamente difíceis de medir, e as dificuldades não são superadas pelas classificações esquemáticas em voga (como personalidades tipo A e B). ${ }^{28}$

Por sua vez, Breilh et al., representantes da chamada epidemiologia social, desenvolveram recentemente trabalhos nos quais postulam o conceito de deterioro de la vida.$^{29} \mathrm{Na}$ base desta abordagem, está a idéia de que o processo de envelhecimento é determinado pelas condições de vida das espécies que demarcam as capacidades de sobrevivência dos fenótipos

24. SUSSER M., "The Epidemiology of Life Stress", op. cit.

25. KASL, op. cit.

26. KASL, op. cit.

27. FEINSTEIN A., Epidemilogic analyses of causation: The Unlearned Scientific Lessons of Randomized Trials. J. Clin. Epidemiol. Vol. $42 \mathrm{n}^{9} 6,1989$.

28. FEINSTEIN A., op. cit.

29. BREILH J., GRANDA E., CAMPAA A., YEPEZ J., PÁEZ R., COSTALES P., Deterioro de la Vida. Corporación Ed. Nacional. CEAS. Quito, 1990. 
produzidos. "A operação dessas condições geno e fenotípicas que desencadeiam o processo 'natural' de envelhecimento estão determinados pelo desenvolvimento das contradições da reprodução social e, todo esse conjunto de processos através de mediações estressantes (nosso destaque), fatigantes, tóxicas, etc. determinam a capacidade máxima de vida da espécie humana (...). "'30 Não interessa, neste trabalho, discutir as proposições metodológicas e discursivas dessa vertente explicativa, mas mostrar a amplitude de uso do conceito de estresse, independentemente das orientações teóricas de seus autores. Será que se referem às mesmas significações?

A rigor, a teoria do estresse propõe explicações com suporte neuro-humoral, mas confunde o como de uma determinada patogenia com o por que tal evento ocorreu com determinada pessoa.$^{31} \mathrm{~A}$ este respeito, pode-se apontar que a teoria do estresse aparentemente elimina o problema de distinguir emoção (pertencente às características da espécie) e emotividade (própria do indivíduo). Segundo a Psicofisiologia, a emoção estaria vinculada ao domínio das manifestações viscerais, endócrinas e metabólicas. Eventualmente, podem ser incluídos comportamentos motores (luta ou fuga). $\mathrm{O}$ terreno da emoção está relacionado à musculatura lisa. A emotividade aponta para um modo singular de reação que certos indivíduos manifestam diante de determinados estímulos. Para a teoria do estresse importa o efeito global. ${ }^{32} \mathrm{~A}$ emoção está principalmente relacionada aos campos das normatividades orgânico-funcional (fisiológica) e social, na medida em que a expressão corporal das emoções está ligada aos modelos de aprendizagem inerentes a cada cultura. ${ }^{33}$ Mas a emotividade refere-se primordialmente ao terreno da normatividade íntima, própria a cada indivíduo, que desenvolve um modo particular de apreender o real no mundo das representações simbólicas. ${ }^{34}$ À teoria do estresse não interessa a subjetividade do "estressado". O que importa é medir as variaçōes de grandezas biológicas e acoplar índices de significação em referência ao estressor em estudo. "O primado do mensurável se impõe em detrimento da experiência subjetiva, a ponto de torná-la acessória, ou mesmo suspeita. A noção de estresse não distingue situações, respostas, vivências." 35 Entretanto, há pertinência na noção de estresse, quando

30. BREILH J., GRANDA E., CAMPAA A., YEPEZ J., PÁEZ R., COSTALES P., op. cit.

31. JEAMMET P., REYNAUD M., CONSOLI S., Manual de psicologia médica. Ed. Masson. São Paulo, 1989.

32. DEJOURS C., O corpo entre a biologia e a psicanálise. Artes Médicas. Porto Alegre, 1988.

33. JEAMMET P., REYNAUD M., CONSOLI S., op. cit.

34. BENOIT P., Psicanálise e medicina. Ed. Jorge Zahar. Rio de Janeiro, 1989. 
aplicada em situações extremas. Um exemplo consiste nos efeitos somáticos da expectativa de práticas de tortura nos campos de concentração. ${ }^{36,37}$ Fora destas condições extremas, o conceito de estresse se torna impreciso. Sua utilização nas pesquisas de base populacional apresenta sérias dificuldades, apesar dos atrativos que seu aparente poder explicativo sugere.

\section{O mal-estar na epidemiologia}

Pode-se afirmar, então, que o processo saúde-doença no nível individual tem características peculiares. As "causas" para a ocorrência do caso são diversas das "causas" responsáveis pela incidência da doença ${ }^{38}$ Dito de outro modo, as razões para a distribuição da doença e a vulnerabilidade dos que adoecem são obscuras. ${ }^{39}$ Será que a epidemiologia dispõe de instrumentos e métodos que permitam transitar por diferentes níveis de organização? Os processos para os quais a epidemiologia busca explicações consistem predominantemente de seqüências previsíveis (convergentes) ou imprevisíveis (divergentes)? Para discutir tais problemas, é preciso desenvolver com mais detalhe estas noções. A teorização subjacente aos níveis de organização se origina no trabalho de Russel e Whitehead sobre os tipos lógicos contidos nos Principia Mathematica, onde se abordam as dificuldades geradas pelo emaranhados lógicos criados pelas passagens por distintos contextos de significação. ${ }^{40}$ Por um lado, é inviável fazer inferências generalizadoras e estabelecer padrões a partir de apenas uma quantidade; por outro, a comparação entre duas quantidades (um dos requisitos básicos para a inferência causal nos estudos epidemiológicos) delimita a geração de um determinado padrão. Ou seja, quantidade e o padrão pertencem a tipos lógicos diversos e seguem racionalidades diferentes. Se não se consegue definir uma classe em função de um único componente de si mesma, as conclusões obtidas mediante a observação de diferenças entre dois conjuntos de elementos prendem-se a distintos tipos lógicos em relação às conclusões geradas a partir de um só elemento. ${ }^{41} \mathrm{O}$ aparente surgimento de um padrão a partir da quantidade se dá onde o

35. DEJOURS C., O corpo entre a biologia e a psicanálise. Artes Médicas. Porto Alegre, 1988.

36. BENOIT P., Psicanálise e medicina, op. cit.

37. UEXKULL T. V., La Médecine Psychosomatique. Gallimard. Paris, 1966.

38. ROSE G., "Indivíduos enfermos y Poblaciones enfermas" in: Boletin Epidemiológico O.P.S. v. 6, no 3, 1985.

39. EASTWOOD M. R., "Epidemiological Studies" in: Psychosomatic Medicine. Int'l J. Psychiatry in Med. Vol. 6 (1/2), 1975.

40. BATESON G., Mente e Natureza. Ed. Francisco Alves. Rio de Janeiro, 1986.

41. BATESON G., op. cit. 
padrão estava látente, anterior aos efeitos da quantidade no sistema. Pode-se fazer uma analogia com o processamento de um filme em negativo, que já sofreu exposição diferenciada à luz, mas que só irá aparecer a partir da revelação. Qualquer fator que determine uma alteração quantitativa produzirá modificaçōes imprevisíveis de padrão. ${ }^{42}$

Agora, vamos enfocar as modalidades de sequiências nos fenômenos da natureza. Podem-se descrever conjuntos de eventos cuja previsibilidade e controle são impossíveis. Por exemplo: o padrão da quebra de uma superfície uniforme de vidro provocado pelo lançamento manual de uma pedra não pode ser previsto a priori; numa corrente de metal com elos homogêneos, submetida a tensão, não se consegue identificar antecipadamente o local de ruptura; no decorrer do aquecimento de água destilada num recipiente de vidro sem irregularidades, não se consegue definir o ponto ou a temperatura ou o momento em que surgirá a primeira bolha. Em suma: estes acontecimentos dizem respeito a comportamentos individuais, casos em que a definição do evento é dada em função da confluência estocástica de uma determinada configuração de variáveis.

Alternativamente, quando se aborda o comportamento de classes de unidades ou populaçôes, é possível fazer-se previsôes. Por exemplo: a resultante da reação química numa mistura iônica de sais; a direção seguida pelas bolas de bilhar, após uma tacada; a fratura óssea após o choque de uma determinada força numa região corporal especificamente vulnerável. Neste caso, o papel da estatística se torna relevante, mas deve ficar claro que suas afirmaçōes se referem a agrupamentos de indivíduos. As leis probabilísticas se localizam entre as descriçōes do comportamento do indivíduo e as descrições da população geral. ${ }^{43} \mathrm{~A}$ atual teorização da Epidemiologia dos Fatores de Risco ${ }^{44}$ está amplamente calcada em afirmativas probabilísticas. Como já foi discutido noutro trabalho, ${ }^{45}$ a noção de fator de risco introduz um atributo de identidade entre o possível e o provável, baseando-se no pressuposto de que o provável é quantificável, e, portanto, previsível. Para isto, é preciso que os objetos estudados (amostras populacionais) sejam comparáveis, o que demanda um certo grau de homogeneização. Assim, tomando certas precauções metodológicas, haveria condiçōes para se fazerem afirmações relativas à população-alvo. ${ }^{46}$ Entāo, a partir de um padräo

\footnotetext{
42. BATESON G., op. cit.

43. BATESON G., op, cit.

44. SILVA G. R., "Avaliaçāo e Perspectivas da Epidemiologia no Brasil" in: Anais do $1^{\circ}$ Congresso Brasileiro de Epidemiologia. Abrasco. Rio de Janeiro, 1990.

45. SCHRAMM F. R. \& CASTIEL L. D., A crise na epidemiologia: a complexidade do processo saúde-doença. Aceito para o $2^{\circ}$ Congresso Brasileiro de Epidemiologia. Belo Horizonte, 1992.
} 
de exposição encontrado numa certa quantidade (amostra considerada representativa de determinada população-alvo), desloca-se o estatuto de fator de risco para o indivíduo, caso haja uma exposição similar. Como vimos, tal transposição está sujeita à confusão de tipos lógicos, o que debilita consideravelmente a capacidade preditiva dos achados epidemiológicos. Este aspecto já mereceu a atenção dos epidemiologistas, ao discutirem os problemas inferenciais originários da hierarquia dos níveis de organização e os conseqüentes riscos de falácia (ecológica ou agregativa conforme o sentido da inferência, ou seja, do mais geral para o menos geral ou vice-versa) ${ }^{47}$ Mas, aparentemente, tais problemas poderiam ser contornados com a utilização de desenhos de estudo mais refinados, rigor metodológico ${ }^{48}$ e modelização matemática. ${ }^{49}$ Outro sério problema refere-se aos fenômenos de interação e sinergismo entre os supostos fatores causais. ${ }^{50}$ Nesta situação, a agregação de diversos elementos gera o surgimento de uma nova qualidade, com a emergência de propriedades que ultrapassam as propriedades dos componentes individuais, tomados separadamente. ${ }^{51}$

A rigor, tais dificuldades não se restringem apenas ao pólo metodológico, mas avançam por domínios da epistemologia. Diversos autores anglosaxônicos se dedicaram a esta área, nos últimos anos. Mas a maior parte da literatura coligida tende a discutir aspectos relativos à aplicabilidade das idéias popperianas ao campo epide-miológico. $52,53,54,55,56,57,58,59$

46. ALMEIDA Fo. N., Avanços conceituais em epidemiologia. Conferência pronunciada em 30 de agosto de 1991. Escola Nacional de Saúde Pública. Fiocruz.

47. SUSSER M., Causal Thinking in the Health Sciences. Oxford Univ. Press. Londres, 1973.

48. SUSSER M., "Epidemiology Today: A Thought-Tormented World” in Int. J. Epidemiol. V. 18 no 3 , 1989.

49. KOOPMAN J. \& WEED D., Epigenesis Theory: A mathematical model relating causal concepts of pathogenesis in individuals to disease patterns in populations. Amer. J. Epidemiol. V. 132 nº 2, 1990.

50. ROTHMANN K., Modern Epidemiology. Little Brown. Boston, 1986.

51. SCHRAMM F. R. \& CASTIEL L. D., A crise na epidemiologia: a complexidade do processo saúde-doença. op. cit.

52. SUSSER M., "Epidemiology Today: A Thought-Tormented World”, op. cit.

53. ROTHMANN K., Modern Epidemiology, op. cit.

54. BUCK C., "Popper's philosphy for epidemiologists". Int. J. Epidemiol. V. 4, 1975.

55. WEED D., "An epidemiologic application of Popper's method." J. Epidemiol. Comm. Health. V. 39, 1985.

56. MACLURE M., "Popperian Refutation in Epidemiology". Am. J. Epidemiol. V. 121. nº3, 1985.

57. WEED L., "On the Logic Causal Inference". Am. J. Epidemiol. V. 123 nº 6, 1986.

58. SUSSER M., "Falsification, verification and causal inference in Epidemiology: Reconsiderations in the light of Sir Karl Popper's philosophy”. in: SUSSER M., Epidemiology, Health \& Society. Selected Papers. Oxford Univ. Press, Londres, 1987.

59. PEARCE N. \& CRAWFORD-BROWND., "Critical Discussion in Epidemiology: Problems with the Popperian Approach”. J. Clin. Epidemiol. V. 32, 1989. 
Mesmo assim, o "mal-estar" na epidemiologia vem sendo assinalado por alguns epidemiologistas. A proliferação as técnicas de análise, viabilizada pelos recursos computacionais, levou à percepção de que "as variáveis analisadas são múltiplas, mas estão freqüentemente divorciadas tanto do substrato biológico como do contex to societal". ${ }^{60}$ No nosso meio, Almeida Filho delineou as características de uma nova proposição paradigmática que lidasse de modo mais satisfatório com os problemas apontados. Assim, teríamos um "objeto totalizado"; "modelos de sistemas dinâmicos" (ou melhor dizendo, instáveis), regidos por "indeterminação" (sistemas de causação circular), descritos por funções não lineares e representados graficamente por atratores (a rigor, atratores estranhos). Modelos deste tipo admitiriam processos inferenciais "estruturais". ${ }^{61}$ Enfim, proposições relacionadas a concepções originadas a partir da chamada teoría do caos. ${ }^{62}$

Ao nosso ver, o foco da questão não se localiza num redirecionamento no nível de paradigmas. Mas, para desenvolver esta posição, faz-se necessária uma breve digressão, baseada nas idéias de Piaget e Garcia. Para eles, o paradigma (concepção criada por Kuhn), consiste num "conceito particular que estabelece o tipo ideal de teoria científica, de modelo a seguir na investigação científica" ${ }^{63}$ Sob a óptica de Kuhn, os requisitos para a aceitação de uma pesquisa científica, a escolha das linhas de investigação e seu financiamento dependem do paradigma dominante na época e no local em questão. Para os autores citados, tal conceito está mais vinculado à sociologia do conhecimento (paradigma social, ligado a fatores exógenos), do que propriamente à epistemologia (paradigma epistêmico, relacionado a fatores endógenos). O que decide o desenvolvimento de determinadas linhas de pesquisa são segmentos sociais que pressionam no sentido de resolução de certos problemas, em detrimento de outros. $O$ paradigma epistêmico aponta para o fato da escolha de temas, idéias e conceitos estar vinculada à aceitação por parte da chamada comunidade científica e a seu aparato conceitual dominante. Assim, o predomínio das correntes reducionistas na epidemiologia resulta da supremacia de um determinado paradigma vigente. $O$ paradigma epistêmico não se assenta diretamente em regras socialmente constituídas, mas, em referência à capacidade interpretativa na busca de soluçōes para os problemas do

60. SUSSER M., "Epidemiology Today: A Thought-Tormented World" in Int. J. Epidemiol. V. 18 n² 3, 1989.

61. ALMEIDA Fo., "Paradigmas em epidemiologia" in Anais do 1º Congresso Brasileiro de Ë̈idemiologia. Abrasco. Rio de Janeiro, 1990.

62. GLEICK J., Caos. A criação de uma nova ciência. Ed. Campus. Rio de Janeiro, 1990.

63. PIAGET J. \& GARCIA R., Psicogênese e história das ciências. Ed. D. Quixote. Lisboa, 1987. 
conhecimento do real postos em determinada época e lugar. Para isto, é necessário entender a origem do processo cognitivo do sujeito. ${ }^{64}$ Deste modo, após uma série de impressões ao longo de sua formação, estabelece-se uma concepção do mundo que interfere na assimilação de qualquer experiência. Para Piaget e Garcia, numa sociedade, a ideologia hegemônica condiciona o tipo de ciência que nela se realiza. Assim, a noção de quadro epistêmico abrange a de paradigma. De tal sorte, que "a cada momento histórico e em cada sociedade, predomina um determinado quadro epistêmico, produto de paradigmas sociais e que é a origem de um novo paradigma epistêmico. Uma vez constituído um determinado quadro epistêmico, torna-se impossivel dissociar a contribuição da componente social daquela que é intrínseca ao sistema cognitivo. Assim, constituído, o quadro epistêmico começa a atuar como uma ideologia que condiciona o desenvolvimento posterior da ciência.(...). É somente nos momentos de crise, de revoluções científicas, que se dá a ruptura com a ideologia dominante e que se passa a um estado diferente com um novo quadro epistêmico distinto do precedente." 65

Desta maneira, diante da atual crise dos paradigmas epistêmicos correntes e da emergência de novas questóes de saúde que se tornam pertinentes na nossa época, a identidade da epidemiologia se transforma com as alterações do quadro epistêmico. Em especial, em função do reconhecimento da necessidade de várias epidemiologias, resultante da constatação da insuficiência das teorias epidemiológicas e de seus operadores em dar respostas satisfatórias aos problemas sanitários contemporâneos. A tal ponto, que se pode afirmar não haver uma teoria geral da epidemiologia: "cada tipo de doença demanda uma teoria ad hoc e, apesar do fato de analogias serem freqüentes e sugestivas, não há limitaçāo essencial quanto ao montante de diferenças que os casos possam diferir". ${ }^{66}$ Isto implica a necessidade de um novo recorte, dentro de um quadro epistêmico que permita especificar diversas identidades próprias a cada disciplina epidemiológica, consoante a magnitude de desenvolvimento obtido nas respectivas áreas de atuaçāo. ${ }^{67}$ Assim, a crise da epidemiologia - na qual os problemas ensejados pela pesquisa do estresse no indivíduo e nas populações desempenham uma função sinalizadora - pode ser explicada a partir

64. PIAGET J. \& GARCIA R., Psicogênese e história das ciências, op. cit.

65. PIAGET J. \& GARCIA R., Psicogênese e história das ciências, op. cit

66. SPERBER D., "Anthropology and Psychology: Towards an Epidemiology of Representations". Man n²0(1), 1985.

67. SCHRAMM F. R. \& CASTIEL L. D., A crise na epidemiologia: a complexidade do processo saúde-doença. op. cit. 
de dois pontos de vista, reciprocamente ligados: 1 . como percepção da corrosão interna e externa das bases teóricas que sustentam a prática e o saber epidemiológicos; 2 . como resultante da complexificação dos modos de apreensão do real, que transforma o quadro epistêmico vigente. ${ }^{68}$

A proposta transdisciplinar, caso venha a ser viabilizada, mediante a integração de conteúdos de outros campos do conhecimento, pode se constituir em recurso importante para compreender a complexidade do processo saúde-doença. Porém, é a alteração do quadro epistêmico que caracteriza uma revolução científica e ultrapassa a mera substituição de paradigmas. Ou seja, o surgimento de um "novo espírito epidemiológico", dentro de uma visão de mundo distinta. Tal circunstância exige o surgimento de uma outra relação entre objeto e sujeito na epidemiologia, de modo a tornar o primeiro menos "fugidio" e o segundo menos "obsessivo", no seu afã infrutífero de controlar o primeiro. Deste modo, seria possível construir conceitos e operadores mais satisfatórios para perceber a diversidade que subjaz à a parente e artificiosa uniformidade dos fenômenos, tal como são lidos pelo instrumento epidemiológico.

\section{RESUMO}

\section{O estresse na pesquisa epidemiológica: o desgaste dos} modelos de explicação coletiva do processo saúde-doença

São enfocadas as dificuldades do instrumento epidemiológico em lidar com as questões postas pelos problemas contemporâneos de saúde, nos quais o conceito de estresse encontra ampla difusão. Assim, apresenta-se uma discussão sobre o arcabouço teórico-conceitual da teoria do estresse e seus desdobramentos. Além disso, são assinaladas as limitações do método e dos modelos epidemiológicos disponíveis ao abordarem: 1. Manifestações cuja previsibilidade não é delimitável; 2. Fenômenos que se encontram em níveis hierárquicos distintos. Nestes casos a teorização subjacente à noção de risco, utilizada para explicar o adoecer referido ao nível individual mostra-se insuficiente. À complexidade do pProcesso saúde-doença demanda outro paradigma epistêmico que permita ao sujeito da ciência epidemiológica desenvolver outras formas de demarcar e compreender seu objeto.

68. SCHRAMM F. R. \& CASTIEL L. D., A crise na epidemiologia: a complexidade do processo saúde-doença. op. cit. 


\section{ABSTRACT \\ Stress in Epidemilogical research: the wear of collecive models of explanation of the health-illness process.}

The article focuses on the difficulties the epidemiological instrument faces when dealing wih questions posed by contemporary health problems, in which the concept of stress finds broad diffusion. Thus there is a discussion about the theoretical-concepual framework of the theory of stress and its developments.

Besides, the text points out the limitation of the method and of the available epidemiological models when they talk about: 1 - manifestations whose predicability cannot be delimited; 2 - phenomena placed in different hierarchic levels. In such cases, the theorization underlying the noion of risk, used to explain sikliness at the individual level proves to be insufficient. The complexity of the health'illness process demands another epistemological paradigm which allaws the subjec of the epidemiological research develop other ways of demarcating and understanding its object.

\section{RESUME}

Le stress dans la recherche épidémiologique: l'érosion des modèles d'explication collective du processus santé-maladie.

Cet article met en lumiére les difficultés des instruments épidémiologiques face aux questions possées par les problèmes contemporains de santé et parmi eux spécialement celui du stress.

Le texte s'occupe aussi de l'analyse de la théorie du stress, les limites méthodologiques des modèles épidémiologiques et les possibilités de construction d'un nouveau paradigme épistémologique pour l'épidémiologie. 